\title{
SYSTEMS AND RELATIONSHIPS FOR CONSTRUCTION QUALITY
}

Submitted to

Special issue on “The Management of Quality in Project Environments” of

International Journal of Quality and Reliability Management

By

Professor Peter Barrett

Research Centre for the Built and Human Environment

University of Salford

SALFORD

M5 4WT

Tel $\quad+44(0) 1612955588$

Fax $\quad+44(0) 1612953862$

Email P.S.Barrett@surveying.salford.ac.uk

1 February 1999 


\section{SYSTEMS AND RELATIONSHIPS FOR CONSTRUCTION}

\section{QUALITY}

\section{Abstract}

This paper argues, with evidence from a number of related studies, that in order to effectively manage quality in the construction project environment, firms need two things. First, externally orientated, flexible, quality improvement systems. Second, a targeted approach to investing in key stable relationships in the supply network of which they are a part.

\section{Keywords}

Quality, construction, supply network, improvement, projects.

\section{Introduction}

The definition of quality can be a complex matter. In construction Baden Hellard (1991) has proposed function, aesthetics, cost and time as the main dimensions.

Through a project involving academic partners from Denmark, Estonia, Lithuania and the UK (CONQUEST, 1995) a concerted effort was made to get to the basics of what construction quality is concerned to address, to produce a common template so that the two ECE countries could be assisted in making the transition from command to market economies drawing from the experience of the EU countries. The exercise was very revealing because the ECE countries had scrapped their highly prescriptive Russian framework, but at that time not really replaced it with anything else, in fact Lithuania had a rule that any mix of regulations from any EU countries could be used. 
This level of turbulence meant that nothing could be taken for granted which was very stimulating.

As a result Baden-Hellard's four quality dimensions were extended through extensive discussions to include environmental and health and safety issues, together with the broader issue of location. This extension of the performance criteria was linked to the notion of a range of stakeholders having various interests in each. Simplistically, it could, for example, be said that "society" is concerned with the environmental dimension, whereas workers and users have a special interest in the safety factors. As a result an interacting mesh of mechanisms exist to address these different interests in these various aspects of performance. In some instances, say for cost, market mechanisms may suffice, for others regulation may be needed.

In this paper, then, quality is taken to be a many-faceted thing, conditioned by many contextual factors and achieved through many mechanisms. It is not simply a specialist subset of general management. If seen in this partial way, it is inevitable that only partial achievements will be possible. Having said that, in construction, as in any industry, it is crucial that client satisfaction is achieved if an organisation is to succeed, or indeed survive. Thus, a key stakeholder is the client, namely the organisation or individual who makes the decision to purchase services from the construction industry.

However, a recent study on the briefing process (Barrett and Stanley, 1999) has cast light on this key relationship. The project methodology was based on a grounded theory approach (Glaser and Strauss, 1967; Strauss and Corbin, 1990), using sixteen 
case study construction projects, carefully selected to provide diversity (Yin, 1989), with data elicited through multiple recorded and transcribed interviews of a range of between two and four project participants. The data was then analysed using soft data analysis software, namely Sage’s well known NUD.ist (Non-numerical, Unstructured Data, indexing, searching, theorising) program. A clear finding, amongst many, was that those in construction have a strong tendency to blame clients for problems because "they [clients] don't understand construction". This is suicidal in business terms and can be seen to explain much of the widely held dissatisfaction with construction. Our proposed definition of briefing sums up the sort of positive aspiration that is needed to underpin action to achieve client satisfaction, namely: Briefing is the process running throughout the construction project, by which means the client's requirements are progressively captured and translated into effect. (Barrett and Stanley, 1999)

So quality in construction can be thought of as the satisfaction of a whole range of performance criteria owned by an interacting host of stakeholders and mediated by a range of mechanisms running from regulation to market forces. Client satisfaction is the ultimate measure of construction quality, but it is clear from the briefing research described above that this will only be achieved if construction companies adopt a strong external orientation in order to address the full range of quality dimensions that impact on the client. Then there is a good prospect that the client will get satisfied users, satisfied statutory authorities, etc, as well as meeting their own direct ends.

This is quite an ambitious target in the complex, dynamic context of the construction project, but it can be argued that meeting expectations is not enough. To really 
succeed expectations must be exceeded (Gronroos, 1984) and the client “delighted”. In this context, two postgraduate research projects have cast some light on the relative importance of various service dimensions. Hoxley (1993) carried out a random postal survey of building surveying practices and their clients. A response rate of around 55\% was achieved resulting in 126 responses from clients and 169 from the practices. There was a strong correlation in the order of importance between the factors as assigned by clients and surveyors surveyed. A high level of responsiveness emerged as a key factor to achieve client satisfaction.

This has been reinforced and extended by a study of exemplary practices carried out by Faulkner (1996). He studied two projects for each of two construction consultancies, each selected by three experienced clients as being their best advisors. Thus, three clients and twelve projects were studied and tracked, with data collected through interviews, and triangulation with other documentary evidence. From this mass of evidence it was found that the practices were judged by the clients in various ways, but with a common core of two factors: value for money (not cheapest) and good team working with other construction participants and with the client. The clients expected the industry to deliver a unified service, not to pass any problem around. The practices:

“[did not] simply respond to client expectations ... the real motivation was for them to achieve 'best in class' status - to the extent of asking 'rude questions', a determination to solve problems and develop a meaningful relationship with their clients ... [but] despite their being regarded as exemplary ... they each acknowledged the potential for further improvement, and demonstrated a determination to aim for increasingly higher levels of service to their clients." 
(Faulkner, 1996, p231)

This evidence suggests that even responsiveness is not enough to achieve excellence. Generative relationships (Senge, 1990) between clients and construction companies and between the companies themselves are needed where new possibilities are created through the interaction between the parties. In addition this needs to be within a climate where improvement is continuously sought.

This introductory section has set the scene for the rest of the paper by drawing together a number of studies of construction. It is suggested that construction quality is a broad concept involving the satisfaction of many interacting stakeholders and that delighting customers demands externally orientated construction companies working in concert with a strong improvement emphasis. The following sections of this paper will consider, within the above context, current activities and future prospects, first taking the company perspective and second looking at the same questions from the perspective of the project. Both views are needed, as the industry comprises, at any point in time, a mesh of many companies working on any one project and any one company working on many projects.

\section{Company-based quality systems}

\section{QA-certification}

Within the UK there has been a presumption that to address quality a company goes for third-party certification against ISO BS EN 9000 (formally BS 5750). The theoretical strengths and weaknesses of this approach have been debated extensively and it is not intended to repeat these arguments here, however, fieldwork evidence in 
relation to construction professionals (included in Barrett and Grover, 1998) is drawn upon to illustrate a few main points. The surveys used were part of a major study completed in 1994, but subsequently included and up-dated through a series of workshops run by the Royal Institution of Chartered Surveyors together with some new surveys that confirmed the earlier findings. The fieldwork adopted multiple perspectives and methods to establish an objective view of QA in construction. The various parts of the methodology are shown in Figure 1. The randomly selected postal surveys provided a triangulated view and generated 146 (48\% response rate) from certified firms; 152 (49\%) from non-certified firms and 51 (29\%) from clients. The view developed from the above data was then linked to a carefully controlled, iterative Delphi study (eg Linstone and Turoff, 1976) using eight experts, one of whom dropped out, chosen to populate a matrix representing a UK perspective from a broad range of disciplines including architects, academics, consultants, clients, and surveyors. The entire exercise was carried out blind, that is none of the experts knew who the others were.

Figures 2 and 3 illustrate two points. First, for those companies that have achieved certification, the actual impact on the quality of the service from the clients' viewpoint has been only slightly positive and does not correlate in any way to the importance of the factors, drawn from Hoxley’s (1993) work. Second, this must be seen in the context that less than half the professional firms in the industry are ever likely to become certified. The projections in Figure 3 were produced by a Delphi panel in 1994, but informed opinion is now that the view, then, for five years hence was, in the event, an over-estimate. 
The argument is simply that QA-certification is by no means the whole answer and for many firms it is not attractive at all. This has been reflected in the findings of a national level review of quality in construction (QLG, 1995). This involved six prominent industry figures, representing all sides of the industry, meeting regularly over a year and a half to develop a strategic view. They concluded, among other things, that quality improvement must be the emphasis for construction. This resonates with a commissioned strategic review of quality in the surveying profession (Barrett and Grover, 1998) that came to a similar conclusion via a synthesis of various studies, additional fieldwork, industry workshops and a structured strategic analysis that took strengths, weaknesses, opportunities and threats and forced paired comparisons to stimulate a raft a possible strategies that were then distilled to a few major thrusts. For this professional grouping the synergy between the notion of professionalism and continuous improvement was important and this study also reinforced the broadening of the quality conception to include issues, such as safety responsibility and positive stewardship of the environment which resonates with the broad view of quality given in the introductory section. The need for an emphasis on professionals working together to do better on a broad front, rather than being driven by overt focused management practices, is evident in Minzberg's (1998) recent paper on managing professionals.

\section{Supple systems}

An approach to quality improvement that has been developed particularly in relation to construction professionals is termed "supple systems" (Barrett, 1994). The genesis of this approach was the development of strategic proposals in the 1994 study shown in Figure 1. The approach advocates the key features set out in Table 1 which 
reflected the findings of the fieldwork, but also linked to the quality literature and literature concerning the management of professional and service industry firms. These ideas have subsequently been tested and extended in the context of higher education as described in Barrett and Sexton (1997). This involved an action research project in which the concepts were tested in a real world situation with an independent researcher observing and recording progress and impact. During this study the notion of stakeholder was introduced in place of client and the importance of a strategic dimension was recognised by the addition of an extra dimension termed "nested objectives”. The idea of the supple systems approach is to either complement ISO 9000 systems for those firms that have followed this route, or to provide an alternative for those firms that do not find this "normal” approach helpful. The supple systems approach is determinedly outwards looking (client / stakeholder orientated), it aims to actively manage the contribution of formal systems alongside other actions, such as leadership, (minimalistic / holistic), it allows diversity, concentrating more on outcomes than detailed processes, but within a strong audit framework (loose-jointed), it encourages incremental improvement (evolutionary) that capitalizes on the positive aspects of the firm's culture (symbiotic with social systems), which in professional firms can contribute a lot of self-control. Lastly, the approach stresses that the systems must be aligned with and contribute to the company's strategy (objectivenested) and in this area a link is currently being developed to "holographic" organisational design (eg Morgan, 1993), which Morgan describes as: "trying to develop approaches to organisation where the whole is built into all the parts” (1993: 176), in order to “create systems that are able to learn from their own experience, and to modify their structure and design to reflect what they have learned” (Morgan and Ramirez, 1983: 4). 
The practical experience of supple systems assessed through action research in the educational context confirmed its general utility to provide a stimulating professional context, allowing autonomy with responsibility. It also revealed many problems and created a lot of data itself that at times could be hard to handle. As a consequence the work on prioritising effort in relation to strategic objectives was pursued, with some success. The approach is a long term endeavour that continues. It works on the capability of the organisation to seek and support continuous improvement.

The supple systems approach endeavours to take into account the nature of professional firms and the fact that they are peopled with highly qualified individuals, who operate within norms provided by their discipline as well as within the particular context of the host firm they work for (Sibson, 1971). It is no accident that at the same time this approach provides a strong basis for flexible external engagement with other members of the supply chain. This is important in the project context, which is the focus of the following section.

\section{Project-based quality systems}

\section{Project quality plans}

Construction is a project-based industry. Temporary teams are constantly being created. Tight QM systems that only make sense internally can cause real problems if they are not compatible with the systems of supply chain partners. A range of possible theoretical outcomes is shown in Figure 4. At present most projects rely on standard contracts to provide project quality management. These are not really designed as quality management tools, but can be effective if the companies involved willingly collaborate. There is a move towards the use of an explicit project quality 
plan. This theoretically links the relevant parts of all of the supply chain participants' own quality systems together around the needs of the project, as shown in Figure 5 (Sjoholt, 1995). This calls for a high level of formalisation and assumes an underlying compatibility if the various players are not going to have to constantly create new systems for each project.

\section{The nature of construction supply chains}

For major projects the investment in comprehensive project quality plans would seem justified, however, a recent study (Barrett and Aouad, 1998) of a sample of three major projects, known to have been successful, raised some interesting questions. The research used Harland's (1996) model of supply chain relationships (see Figure 6) which provides a gaps model stressing the softer aspects, namely the perceptions on the part of customers and suppliers of requirements and performance. The study took as a starting point any one participant in the given project who then gave other contacts upstream and downstream through a "snowballing” technique. Each “player” was asked questions through telephone interviews, using a standard interview format, which took between twenty minutes and one hour, concerning the communications that took place and the respondent's perceptions of the clarity of the requirements they were charged with meeting and their degree of success in this context. Harland's approach links well to the service industry quality literature (eg PZB, 1985) and the TQM customer-supplier-chains notion, and it takes a richer view than the usual technical logistics perspective, which prevails in construction research on supply chains (O’Brien, 1997). By asking those involved at each end of any given link about their perceptions gaps could be identified and related to performance. It became clear that, in fact, supply networks typified construction. The relationships 
were much more complicated than purely linear "relay-race” connections. This was particularly so for specialist design. Figure 7 provides an illustration of part of a supply network studied.

Trawling through the interview records it became evident that the relationships in these successful projects were consistently typified by a high level of interaction: daily meetings, constant communications (or “fax and build”!, “no time for letters”, “informally short-circuited”, “all decisions in meetings”) and the use of radio links. This reinforces the importance of responsive or, better still, generative working. Several of the relationships were not new, participants were working with partners they had experience of from previous projects. This clearly led to a lower level of misunderstandings. Quotations such as: “good relationship”, “team players” and “worked closely and successfully together” are common. This is underpinned by a high level of commitment. "Never let down ... even at 3 O’clock in the morning”! These factors, that were crucial to the success of the projects, did not depend on formal systems, in fact there is the distinct impression that the communications and relationships described replaced the formal checking systems which could not cope with the complexity and turbulence of the project demands. The idea of responses being appropriate to the demands faced is not new (Burns and Stalker, 1961; Lawrence and Lorsch, 1967) and links to the need for requisite variety in the organisation (eg Beer, 1985). The point being made is that, in the dynamic, project environment, although a framework is needed, at a more detailed level it seems likely that multiple informal communications within the context of strong relationships are the key to success. 


\section{Managing the supply network}

In a sense what is emerging is that, in order to achieve high quality outcomes, managing relationships is a crucial skill in a project-based industry where temporary coalitions are constantly forming and breaking up. This argues for an investment by those in the industry, but how best to maximise that investment in terms of productive relationships given finite resources? This links back to the strategic dimension of supple systems. Just as the quality systems of a company should support to best effect the company strategy, so too should the company's relationships provide optimum support to its role, position and aspirations in the industry.

Many players in the industry are currently thinking about developing strategic alliances and framework agreements. Of course some major clients, such as BAA and Boots have made a lot of progress, but for many more normal players it is still struggling to get past the initial idea. It is difficult to identify key relationships without a model or vocabulary to do so. A recent project, entitled "Integrating to Innovate” (i2i), addressed this question focussed on innovation in construction across the supply chain (Barrett and Sexton, 1998). The project methodology placed great importance on the creation of an industry-based project team that had members from right across the supply network, including: a materials manufacturers, a builders supplier, a specialist sub-contractor, a contractor, a client and a facilities manager. A series of meetings were held over a year in which discussions were held and then a workbook created made up of a summary of the ideas generated plus questions. Responses to this were then analysed and provided the starting point for the next meeting. In addition visits were conducted to the partners sites and mini-projects pursued with them and this provided much additional data and material for the 
workshops. The cycle of meetings allowed a good level of trust and familiarity to grow up between the partners so that a lot of tacit knowledge flowed around a concerted effort to identify major common issues and themes.

Interestingly, the project quickly confirmed that the scope for any company to innovate is severely limited if it tries to act on its own. So much depends on the other partners with whom it works. This translates very clearly for quality. A company can only achieve a little on its own. To radically address quality it needs to work with its supply network partners. With the close involvement of the industry collaborators, the project produced after a number of iterations a model that provides five levels of possible interaction. This is given in Figure 8 and ranges from a simple one-way exchange within a project at Level 1 up to a joint business-based approach to innovation at Level 5 within which tacit as well as explicit knowledge is regularly exchanged. Table 2 was also developed with the partners to illustrate in more detail what the levels mean in practice.

This model and vocabulary then link to a decision process, again jointly developed, that firms can go through to identify and prioritise their supply chain relationships as shown in Figure 9. The end result is intended to be a focused investment in building a portfolio of key relationships that will help the company deliver high quality services and achieve its long-term goals. In a fragmented, project-based industry this is probably one of the most productive actions a firms can take to achieve quality - and innovation - in its services. If a construction project is seen in change management terms, it could be said that companies taking the above approach are trying to stabilise their “guiding coalition” (Kotter, 1996). 
Interestingly, this ability to manage supply chain relationships is considered so important and distinctive in the construction context, that it is being linked into a project that is taking the capability maturity (SEI, 1994) approach to organisational system assessment and development drawing from the computer software industry into construction (Sarshar et al, 1998). The CMM model defines system maturity levels ranging from chaotic, through repeatable, defined, managed, to optimising. The approach argues for creating platforms at each level before attempting more sophisticated activities. This thinking has some relevance for supply network relations, as the shared platform defined by the lowest performer will be a strong determinant of the level at which shared action can take place. However, in the context of shared quality improvement efforts, the platform may well be defined by the level of the relationship management and innovation capabilities in the companies.

\section{Summary and conclusion}

This paper is based on a synthesis of a number of studies all of which are quite substantial in their own right, however, the objective is to try to reveal a bigger picture linked and grounded back into the data of these empirical studies. Some of the data is statistical, but much of it is soft data analysed using qualitative methods. Guba and Lincoln (1989) suggest the following criteria for assessing the "authenticity" of qualitative research: resonance, rhetoric, empowerment and applicability. These are briefly applied to the content of this paper before the findings are summarised and conclusions drawn.

"Resonance" is the extent to which the research process reflects the underlying paradigm. The topic is highly subjective and involves many participants interacting 
through complex relationships. The combination of studies followed by synthesis is resonant with these characteristics. "Rhetoric" is concerned with the strength of the argument presented. By linking multiple views to synthesise the major issues a strong and relatively simple case has been presented for making improvements in construction project quality. This links to "empowerment", that is enabling readers to take action. There is a clear agenda, but it remains to be seen if these findings, illustrated as they are, will lead to concerted action in a combative industry. The explicit consideration of the context for implementation should help together with the high "applicability" of the findings, achieved through keeping visible the basis of the proposals. It seems from industry feedback over several years on various discrete aspects of the proposals that everyone can find something in the material that confronts them and is meaningful in their everyday lives. Indeed the industry collaborative nature of the research that is being drawn upon ensures this.

In overall summary then, clearly a certain level of formal systems are necessary, but there is plenty of evidence that they are not sufficient to achieve high quality, especially in the turbulent, complex world of construction, where temporary organisational forms are the main mode of project delivery.

In order to achieve continuous improvement and effective joint working firms need dynamic quality systems that are externally orientated and flexible. Supple systems has been described as an approach that meets these criteria and also harnesses the professionalism available. 
Taking a broader view than the single company, supply network issues have been considered. Models, designed originally for joint innovation activity, have been described and seem to fit well the need to create some stability in the companies relationships so that joint quality improvement can be sought across the supply network. The thrust is to get firms to target their efforts into building key relationships. These can then provide a measure of stability out of which long-term, incremental improvement can be achieved. Supple systems can be seen as a way of developing these types of relationships for those parts of the supply network that exists within companies. Thus, the approaches being advocated are highly complementary.

A combination of sound formal systems and strong relationships is essential to achieve high quality in the project environment of construction, both within companies and across the supply network. There will be great variability in the industry, but in many firms strong steady-state orientated formal systems need to be matched by dynamic, less formal relationships or they may well diminish overall project effectiveness. Conversely many networks are a morass of personal connections that are too fragile and should be buttressed by the creation of a portfolio of more formal key alliances. If the right balance can be achieved and actively managed, it is my belief that a powerful force for positive change can be created.

\section{Acknowledgements}

The author would like to take this opportunity to acknowledge the input of many friends and colleagues who appear as co-authors of several of the papers referenced, in particular Martin Sexton has worked closely on many of the research projects drawn from. The work has generally involved collaboration with industry and thanks 
are due for this willing (for them) and stimulating (at least for me) involvement that has been crucial to the relevance of the findings. Funding for various projects drawn from has been provided by the UK Engineering and Physical Sciences Research Council and the Department of the Environment, Transport and the Regions and this continued support has been crucial to building a clearer picture. I must thank the editor and referees for stimulating comments that improved the paper, but, as ever, responsibility for any errors or omissions remains mine.

\section{References}

Baden-Hellard, R., 1991, “Total Quality Management in Construction Management”, in Practice Management: New Directions for the Construction Professional, edited by P.Barrett and R.Males, E\&FN Spon, London.

Barrett, P.S., 1994, “Supple Systems for Quality Management”, RICS Research Paper Series, RICS: London.

Barrett, P.S. and G.Aouad, 1998, Final Report: Hybrid Concrete Structures for the UK Market, Workpackages 3 and 5, PiT Project CI39/3/372, Reinforced Concrete Council, Reading.

Barrett, P.S. and R.Grover, 1998, Quality Assurance and the Surveying Professional, 3 vols, RICS, London.

Barrett, P.S. and M. Sexton, 1997, Improving Quality in a Research-orientated University Department Using Supple Systems, Final Report to the Higher Education Quality Council, University of Salford. 
Barrett, P.S. and M. Sexton, 1998, Integrating to Innovate, Construction Industry Council, London.

Beer, 1985, Diagnosing the System for Organizations, Wiley, Oxford.

Burns, T. and G.M.Stalker, 1961, The Management of Innovation, Tavistock Publications, London.

CONQUEST, 1995, Achieving quality management in construction, Final report for EC PHARE ACE project, December 1995

Faulkner, A.J., 1996, Achieving Exemplary Quality in the UK Construction Professions, unpublished PhD thesis, University of Salford, UK.

Glaser, B.G. and A. L. Strauss, 1967, The Discovery of Grounded Theory, Aldine, Chicago.

Grönroos, C., 1984, Strategic Management and Marketing in the Service Sector, Chartwell-Bratt, Bromley.

Guba, E. and Lincoln,Y., 1989, Fourth Generation Evaluator, Sage, Newbury Park, California, 1989 (quoted in G.Symon and C.Cassell, Qualitative Methods and Analysis in Organisational Research: A Practical Guide, SAGE Publications, London, 1998, p 7). 
Harland, C.M., 1996, “Supply Chain Management: Relationships, Chains and Networks”, British Journal of Management, Vol 7, Special Issue, S63-S80.

Hoxley, M., 1993, Obtaining and Retaining Clients: A Study of Service Quality and the UK Building Surveying Practices, unpublished MPhil thesis, University of Salford, UK.

Kotter, J.P., 1996, Leading Change, HBS Press, Boston.

Lawrence, P.R. and J.W.Lorsch, 1967, Organisation and Environment: Managing Differentiation and Integration, Harvard, Boston.

Linstone, H.A. and M. Turoff (Eds), 1976, The Delphi Method, Techniques and Applications, Addison-Wesley, Reading, Mass. USA.

Minzberg, H., 1998, “Covert Leadership: Notes on Managing Professionals”, HBR, Nov-Dec, pp141-147.

Morgan, G., 1993, Imaginization: the art of creative management, Sage, London.

Morgan, G. \& Ramirez, R., 1983, “Action Learning: A Holographic Metaphor for Guiding Social Change”, Human Relations, 37: 1: 1-28. 
O,Brien, W.J., 1997, “Construction supply-chains: Case study, integrated cost and performance analysis”, Lean Construction, edited by L.Alarcón, A.A.Balkema, Rotterdam, Netherlands, pp187-222.

Parasuraman, A., V.Zeithaml and L.Berry, 1985, “A Conceptual Model of Service Quality and Its Implications for Future Research”, Journal of Marketing, No 49 (Fall), pp41-50.

QLG, 1995, Constructing Quality: A Strategy for Quality in Construction, Department of the Environment, London.

Senge, P.M., 1990, The Fifth Discipline: The Art and Practice of the Learning Organization, Doubleday: New York.

SEI, 1994, The Capability Maturity Model, Addison-Wesley, Reading Mass.

Sibson, R.E., 1971, Managing Professional Services Enterprises: The Neglected Frontier, Pitman, New York.

Sjoholt, O, 1995, From Quality Assurance to Improvement Management, Project Report 189, Norwegian Building Research Institute, Oslo.

Strauss, A.L. and Corbin, J., 1990, Basics of Qualitative Research: Grounded Theory Procedures and Techniques, Sage, Newbury Park, California. 
Yin, R., 1989, Case Study Research - Design and Methods, Sage Publications,

Newbury Park, California. 
Table 1: Key Features of Supple Systems

\begin{tabular}{|c|c|c|}
\hline Symbol & Feature & Description \\
\hline & Objective-nested & $\begin{array}{l}\text { The systems are aligned to, and positively support, } \\
\text { appropriate strategic organisational objectives. Systems } \\
\text { should not be developed within an operational/technical } \\
\text { vacuum. }\end{array}$ \\
\hline & $\begin{array}{l}\text { Client / Stakeholder } \\
\text { orientated }\end{array}$ & $\begin{array}{l}\text { The systems are tested against stakeholder, and especially } \\
\text { client requirements, by actively seeking feedback through } \\
\text { both hard and soft data. }\end{array}$ \\
\hline & Minimalist / Holistic & $\begin{array}{l}\text { "As much as you must, as little as you may", that is, not } \\
\text { having systems for their own sake, but rather targeting high } \\
\text { risk / gain areas. Better to have made some progress on } \\
\text { all important fronts than to have patchy provision. }\end{array}$ \\
\hline & Loose-jointed & $\begin{array}{l}\text { The systems operate at an audit level: clarifying objectives, } \\
\text { checking performance and integrating efforts. At an } \\
\text { operational level different styles and approaches can be } \\
\text { accommodated, especially when they have proved } \\
\text { themselves over time. }\end{array}$ \\
\hline & Evolutionary & $\begin{array}{l}\text { Allow incremental and continuing progress to be made from } \\
\text { whatever base. }\end{array}$ \\
\hline & $\begin{array}{l}\text { Symbiotic with social } \\
\text { systems }\end{array}$ & $\begin{array}{l}\text { Build on the norms and culture of the organisation, for } \\
\text { instance allowing self-control or group pressure to operate } \\
\text { where appropriate. }\end{array}$ \\
\hline
\end{tabular}




\section{Table 2: Innovation levels and associated activities}

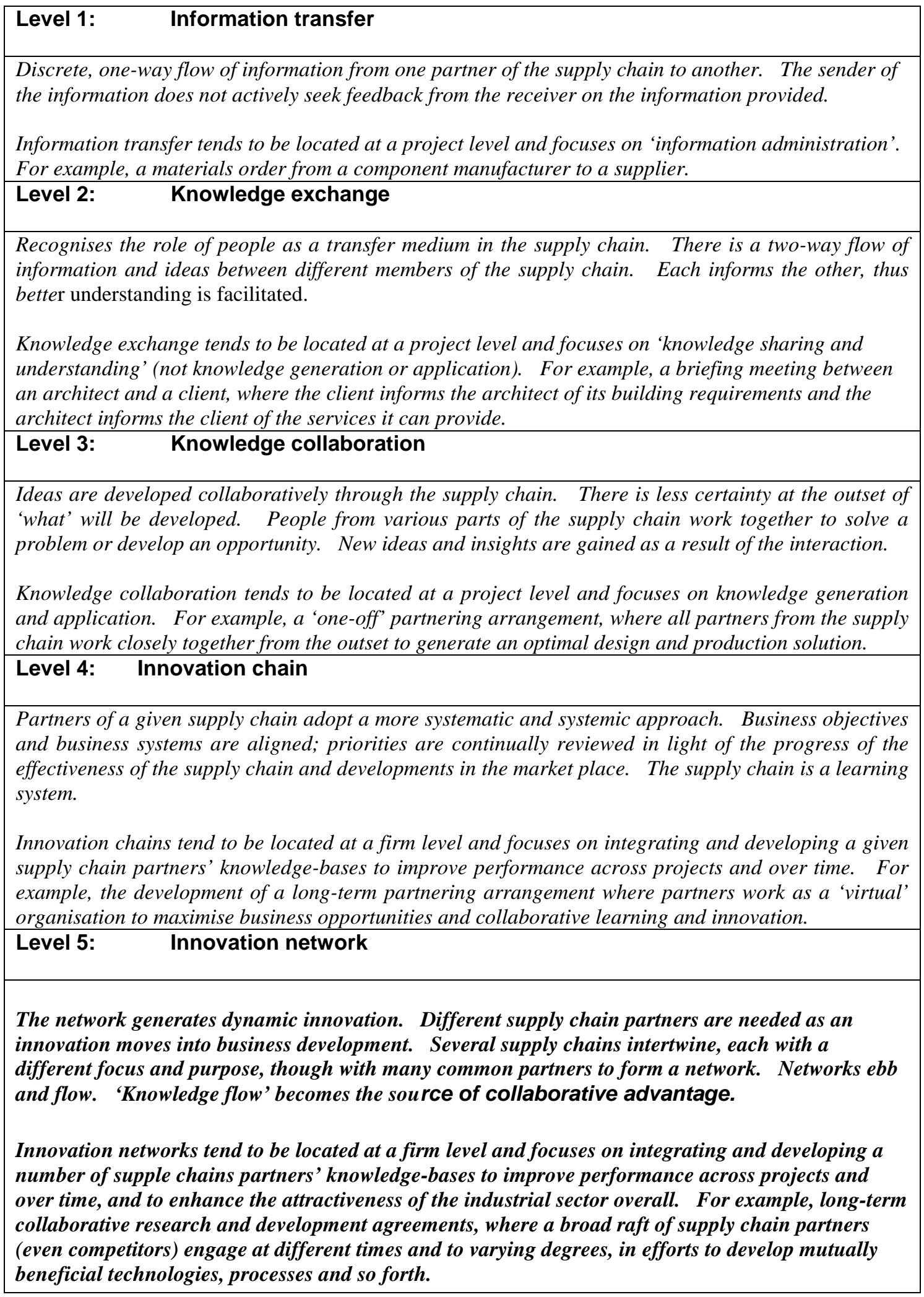

